[Agr. Biol. Chem., Vol. 30, No. 2, p. 142 148, 1966]

\title{
Studies on Pectic Enzymes of Microorganisms
}

\author{
Part II. Production of Endo-Polygalacturonase with \\ Aspergillus saitoi*
}

\author{
By Makari Yamasaki, Tsuneo Yasui ${ }^{* *}$ and Kei Arima \\ Department of Agricultural Chemistry, Faculty of Agriculture, The University of Tokyo \\ Received August 18, 1965
}

\begin{abstract}
Conditions for the production of endo-polygalacturonase (endo-PG) with Aspergillus saitoi IAM 2217 in the submerged culture was examined. This strain was selected as the most potent producer of endo-PG. Endo-PG of this strain was produced in the absence of pectin, but the addition of pectin increased endo-PG activity when inoculated with proliferated mycelia.

As far as examined with d modified Czapek medium (ordinary constituents + pectin and ammonium tartrate), the addition of organic nitrogen sources, such as corn steep liquor, markedly reduced the enzyme producibility. As for the carbon and nitrogen amount in the medium, sucrose: $4 \%$, pectin: $2 \%, \mathrm{NaNO}_{3}: 1.15 \%, \mathrm{C} / \mathrm{N}=10$, gave the best result among tested.
\end{abstract}

\section{INTRODUCTION}

In the previous paper, ${ }^{11}$ it was reported that molds which specifically produced one of several pectic enzymes were isolated and that a few strains of Aspergillus saitoi were the specific potent producers of endo-polygalacturonase (endo-PG).

Endo-PG is known to split the $\alpha$-1,4-glycosidic linkage of polygalacturonic acid at random. ${ }^{2,31}$

On the contrary, the real presence of polymethylgalacturonase (PMG) which is thought to split directly the glycosidic linkage of pectin in hydrolytic way, is very uncertain, although it has been reported that the activity of pectin trans-eliminase which directly and eliminatively split the $\alpha$-1,4-glycosidic linkage

\footnotetext{
* This report was presented at the Grand Meeting of Kanto Section of Agricultural Chemical Society of Japan, Tokyo, April 1, 1964.

** Present Address: Faculty of Agriculture, Tokyo University of Education, Komaba cho, Meguro-ku, Tokyo.

1) K. Arima, M. Yamasaki and T. Yasui, This Journal, 28, 248 (1964).

2) A. L. Demain and H. J. Phaff, Wallerstein Lab. Comm., 20, 119 (1957).

3) H. Deuel and E. Stutz, Adv. Enzymol., 20, 341 (1958).
}

of pectin molecules was actually found in fungal pectinase preparations. ${ }^{4,5}$

Endo-PG is thought, therefore, to have the most important role in the enzymic degradation of pectic substances if pectinesterase coexist. Then the authors aimed at the production of endo-PG in the submerged culture with the specific potent producer, Aspergillus saitoi, and the purification of this enzyme from the crude enzyme preparation.

Saitô $^{61}$ and Tuttobello et al. ${ }^{71}$ already reported the production of polygalacturonases by Aspergillus niger in the submerged culture.

According to the result of Saitô, ${ }^{61}$ endo-PG was constitutive throughout the culture periods. On the contrary, Tuttobello et al. "found that the addition of pectin to the culture medium greatly increased the amount of endo-PG excreted to the medium, although the pro-

4) P. Albersheim, H. Neukom and H. Deuel, Helv. Chim. Acta, 43, 1422 (1960).

5) R. D. Edstrom and H. J. Phaff, J. Biol. Chem., 239, 2403, 2409 (1964).

6) H. Saitô, Y. Minoda and H. Marumo, J. Agr. Chem. Soc. Japan, 28, 810 (1954).

7) E. Tuttobello and P. J. Mill, Biochem. J., 79, 51 (1961). 
duction of endo-PG was observed in the absence of pectic substances.

Aspergillus saitoi is closely related to Asp. niger, but this species is defined as the different one from Asp. niger in our country. ${ }^{81}$ Both Asp. niger and Asp. saitoi have black conidia, less than $5 \mu$ in diameter, and cannot assimilate nitrous acid.

The matured conidia of Asp. saitoi, however, is characterized with smooth or rough surface in comparison with the matured conidia of Asp. niger with conspicuous echinulae or spinules.

It is the purpose of this report to inform the cultural conditions for the production of endo-PG by the submerged culture with the specific potent producer, Aspergillus saitoi IAM 2217 .* $^{*}$

\section{MATERIALS AND METHODS}

\section{Culture medium}

Unless otherwise stated, a modified Czapek medium was employed throughout this study, which contained sucrose, pectin N. F.** (Sunkist Growers, Inc., Ontario, Calif., U.S.A.), $\mathrm{NaNO}_{3}, 0.5 \%$ of ammonium tartrate, $0.1 \sim 0.2 \%$ of $\mathrm{K}_{2} \mathrm{HPO}_{4}, \quad 0.5 \%$ of $\mathrm{KCl}, 0.05 \%$ of $\mathrm{MgSO}_{4} \cdot 7 \mathrm{H}_{2} \mathrm{O}$, trace of $\mathrm{FeSO}_{4}$, and $0.003 \%$ of yeast extracts.

The concentration of sucrose, pectin N.F., $\mathrm{NaNO}_{3}$ was varied according to experimental purposes and will be mentioned in detail in each experiment.

\section{Culture conditions}

Usually the conidia of Aspergillus saitoi IAM 2217 were inoculated to a bread medium which was solely composed of autoclaved wet bread. After three or four days' culture at $30^{\circ} \mathrm{C}$, the surface of the bread was covered with black conidia, which were collected with pouring sterilized distilled water containing $0.05 \%$ of sucrose monostearate. The conidia thus obtained were inoculated to $100 \mathrm{ml}$ of the inoculum medium (sucrose: $3 \%$, pectin N.F.: $0.75 \%, \mathrm{NaNO}_{3}$ : $0.58 \%, \mathrm{C} / \mathrm{N}=10$ ) contained in the $500 \mathrm{ml}$ shaking flask at the final concentration of $1.0 \sim 1.5 \times 10^{6}$ conidia $/ \mathrm{ml}$.

After being cultured for $42 \sim 48$ hours on a recipro-

8) K. Sakaguchi, H. Iizuka and S. Yamazaki, Ôyôkingaku, 3, $97(1950)$.

* Formerly reported as Asp. saitoi 4-3.

** N. F.: National Formulary. cal shaker at 125 oscillation per minute, an amplitude of $7.5 \mathrm{~cm}, 30^{\circ} \mathrm{C}, 6 \sim 7 \mathrm{ml}$ of the developed mycelial suspension was transferred to $100 \mathrm{ml}$ of the main culture medium in $500 \mathrm{ml}$ shaking flasks and cultured at 100 o.p.m., an amplitude of $7.5 \mathrm{~cm}$ and $30^{\circ} \mathrm{C}$. The concentration of sucrose, pectin N. F., and $\mathrm{NaNO}_{3}$ of the main culture medium will be mentioned in individual experiment as stated above. The activity of endo-PG in the main culture medium was assayed periodically.

\section{Evaluation of endo-PG activity}

Endo-PG activity was measured after Saitô's method by the decrease in viscosity of sodium polypectate (Sunkist Growers Exchange Lot 9649) using an Ostwald viscosimeter.9) One viscosity diminishing unit was defined as the amount of enzyme which reduced the viscosity of $1 \mathrm{ml}$ of a $0.8 \%$ solution of sodium polypectate by $50 \%$ in 10 minutes at $\mathrm{pH} 4.5$ and $40^{\circ} \mathrm{C}$.

To $5 \mathrm{ml}$ of $0.8 \%$ of sodium polypectate solution which contained final $0.05 \mathrm{M}$ acetate buffer $\mathrm{pH} 4.5$, $0.2 \mathrm{ml}$ of appropriately diluted enzyme solution was added. The reaction mixture was transferred to an Ostwald viscosimeter whose substrate blank and water blank were 90 and 6.5 seconds respectively. Fig. 1 shows the standard curves for endo-PG assay. Per cent viscosity change, expressed in Fig. 1, was calculated from Roboz et al.'s equation.10?

$$
\text { Per cent viscosity change }=\frac{V_{o}-V_{t}}{V_{o}-V_{s}} \times 100:
$$

where

$V_{0}=$ flow time in seconds of Na-polypectate + inactivated enzyme (substrate blank)

$V_{t}=$ flow time in seconds at reaction time of $\mathrm{Na}$ polypectate +active enzyme

$V_{s}=$ flow time in seconds of the solvent + inactivated enzyme (water blank).

\section{Evaluation of endo-PMG activity}

Endo-polymethylgalacturonase (endo-PMG) activity was measured in the similar way as done for the endo-PG activity assay using $1.3 \%$ pectin solution (containing final $0.05 \mathrm{M}$ acetate buffer $\mathrm{pH} 3.5$ or 4.5 ) and the same Ostwald viscosimeter.

\section{Simplified evaluation of endo-PG activity}

The activity of endo-PG was in part estimated by the disk plate method as previously reported.1) In

9) H. Saitô, J. Agr. Chem. Soc. Japan, 28, 814 (1954).

10) E.R. Roboz, R. W. Barrat and E. Tatum, J. Biol. Chem., 195, 459 (1952). 


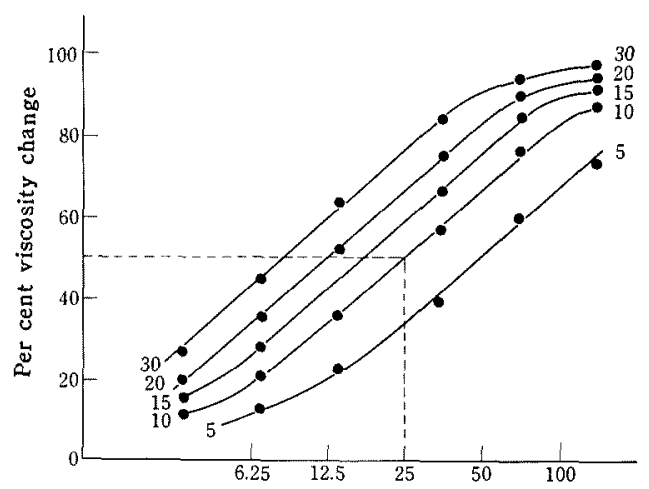

Endo-PG activity (unit/ml, log. scale)

FIG. 1, Standard Curves for Endo-PG Activity. Reaction time is shown in minutes.

this experiment, however, pulp disks (Tôyô Filter Paper Co.), $8 \mathrm{~mm}$ in diameter, were used in stead of the disks made of Tôyô filter paper No. 2. The standard curve was prepared by placing the disks moistened with the serial concentration of the enzyme solution of known activity and the activity of endoPG was expressed in the unit as defined above.

\section{Chromatography of galacturonides}

To $5 \mathrm{ml}$ of $1 \%$ polygalacturonic acid solution, which was previously adjusted to $\mathrm{pH} 4.8$ with final $0.05 \mathrm{M}$ acetate buffer, $0.2 \mathrm{ml}$ of the culture filtrate was added. The enzyme reaction was carried out at $30^{\circ} \mathrm{C}$. Aliquots of $15 \mu \mathrm{l}$ of the mixture were withdrawn periodically and applied to a Tôyô filter paper No. $50(40 \times 40 \mathrm{~cm})$. The paper was ascendingly developed with butanol-acetic acid-water $(5: 2: 3)$. Aniline phthalate was used as a color reagent.

\section{RESULTS}

The selection of potent producers of endo-PG

In the previous paper, ${ }^{11} 6$ strains of mold were isolated as the most potent producers of endo-PG. These strains were further examined for their enzyme producing ability in a shak. ing culture. Mycelia or conidia were inoculated to $10 \mathrm{ml}$ of the modified Czapek medium mentioned above placed in $20 \times 200 \mathrm{~mm}$ test tubes, which were shaken for five days at $30^{\circ} \mathrm{C}$. The concentration of sucrose, pectin N.F., and $\mathrm{NaNO}_{3}$ of the medium were fixed at $2,0.5$ and $0.2 \%$ respectively. In this experiment, endo-PG activity at $\mathrm{pH} 3.5$ and endo-PMG activity at $\mathrm{pH} 3.5$ and 4.5 were also measured. Aspergillus saitoi 4-3 (IAM 2217), as shown in Table $I$, had the highest endo-PG producing ability. Thus this strain was further examined for its cultural conditions.

\section{The effect of pectin on the production of endo-} PG

In order to know whether the endo-PG of Asp. saitoi IAM 2217 is constitutive or induced enzyme, the following experiment was carried out. At first, conidia of $A s p$. saitoi, at $1 \times 10^{6}$ conidia per $\mathrm{ml}$ of the medium, were inoculated to the ordinary Czapek medium (sucrose: $2 \%$, $\mathrm{K}_{2} \mathrm{HPO}_{4}: 0.1 \%, \mathrm{NaNO}_{3}: 0.3 \%$, KCl: $0.05 \%$, $\mathrm{MgSO}_{4} \cdot 7 \mathrm{H}_{2} \mathrm{O}: 0.05 \%, \mathrm{FeSO}_{4}$ : trace) containing $1 \%$ of pectin or $1 \%$ of sucrose instead of pectin, and shaken at 125 o.p.m. for 2 days at $30^{\circ} \mathrm{C}$. Then about $7 \mathrm{ml}$ of the suspension of mycelia of the plus pectin flasks were

TAble I. Comparison of Endo-PG Producing Ability of Several Strains of Mold in a MODIFIED CZAPEK MEDIUM

Asp. saitoi 4-3 (IAM 2217)

Asp. saitoi 7-6

Pen. islandicum Sopp 777

Pen. islandicum Sopp 1270

Pen. islandicum Sopp 1212

Asp. nakazawai $1 \mathrm{I}-8$

$\begin{array}{cc}\text { Endo-PG activity (unit/ml) } \\ \text { at } \begin{array}{c}\text { pH } 3.5 \\ 160\end{array} & \text { at } \mathrm{pH} 4.5 \\ 79 & 1,100 \\ 12 & 530 \\ 9 & 43 \\ 7 & 43 \\ 12 & 12 \\ & 48\end{array}$

\begin{tabular}{|c|c|}
\hline \multicolumn{2}{|c|}{ Endo-PMG activity (unit $/ \mathrm{ml}$ ) } \\
\hline at $\mathrm{pH} 3.5$ & at $\mathrm{pH} 4.5$ \\
\hline 165 & 650 \\
\hline 74 & 300 \\
\hline 21 & 22 \\
\hline 21 & 22 \\
\hline 8 & 8 \\
\hline 10 & 16 \\
\hline
\end{tabular}

(after 5 days' shaking culture) 
transferred to the same new Czapek medium containing $1 \%$ pectin or another $1 \%$ of sucrose. The mycelial suspensions from flasks without pectin were also transferred similarily to the new Czapek medium containing pectin or no

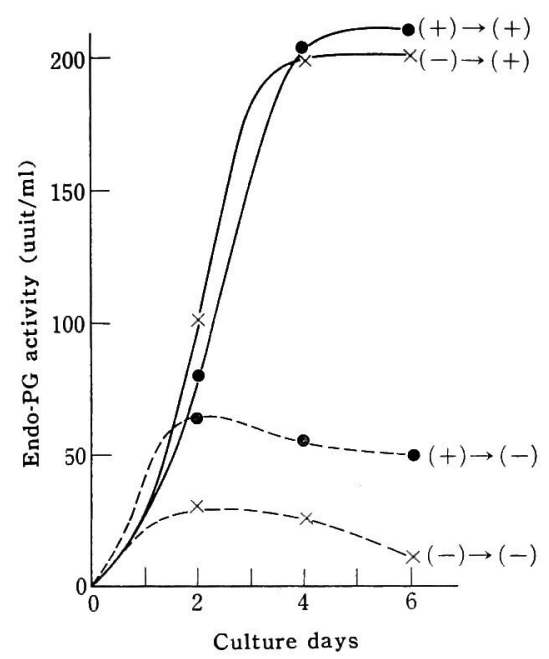

FIG. 2. The Effect of Pectin on the Production of Endo-PG When Inoculated with Mycelia.

The symbols $(+)$ and $(-)$ stand for pectin containing and minus media repectively, and the symbol $\rightarrow$ stands for a transfer. pectin.

Then the shaking flasks were shaken at 125 o.p.m., $30^{\circ} \mathrm{C}$, and the endo-PG activity was measured periodically by the disk plate method. The result is shown in Fig. 2. The detectable amount of endo-PG was found in the pectin minus flask inoculated with mycelia grown in the pectin minus medium. But the addition of pectin to the medium markedly increased the endo-PG activity.

As shown in Fig. 3, the chromatographic patterns of the enzymic hydrolysates were different between pectin plus lots $((+) \rightarrow(+)$, and $(-) \rightarrow(+))$ and pectin minus lots $((-) \rightarrow(-)$, and $(+) \rightarrow(-))$.

Comparison between inoculating conidia and mycelia

When conidia of Asp. saitoi IAM 2217 were directly inoculated to the modified Czapek medium, not only the effect of pectin on the formation of endo-PG was not observed, but the endo-PG activity in the same experimental lot was fairly fluctuated between flasks.

But this fluctuation was partly overcome by inoculating mycelia instead of conidia. Thus two sorts of the modified Capek media were provided, the one for the inoculum medium,

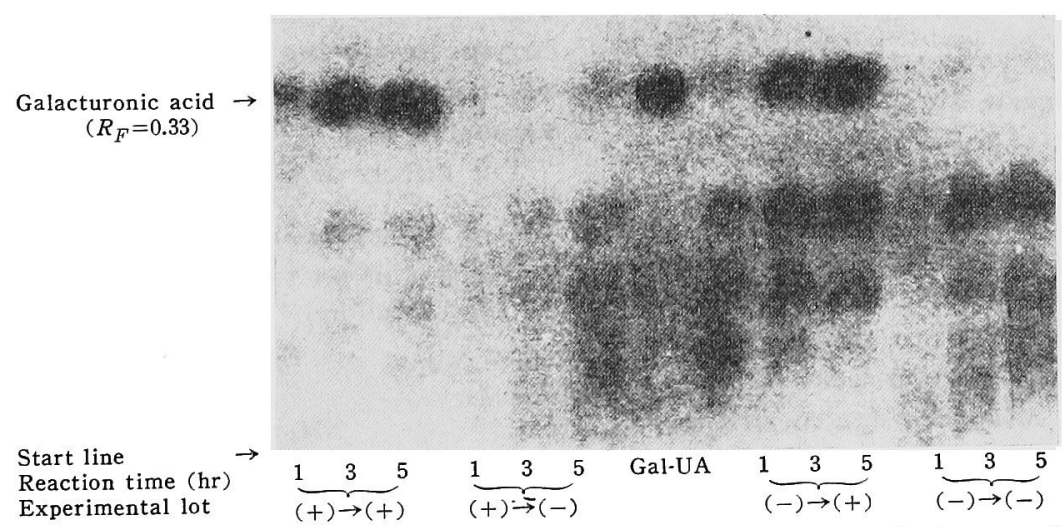

FIG. 3. The Chromatographic Patterns of the Enzymic Hydrolysates of Polygalacturonic Acid.

The enzyme solutions, i.e., culture filtrates, were obtained from 6 days' culture fter the mycerial suspensions were transferred to the new medium.

The symbo!s used for the experimental lots are the same ones as defined in Fig. 2. 
and the other for the main culture medium. The enzyme activity in the main culture medium was followed periodically after the mycelia proliferated in the inoculum medium were inoculated. As shown in Figs. $4 \mathrm{~A}$ and $4 \mathrm{~B}$, the inoculation of mycelia proliferated in the inoculum medium gave fairly higher activity than direct inoculation of conidia.

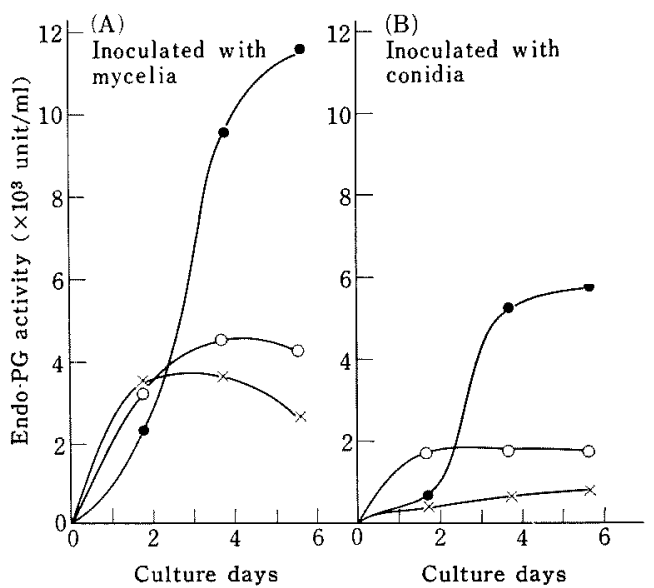

FIG. 4. Effects of the Type of Inoculation and Organic Nitrogen Sources on the Development of Endo-PG Activity of Aspergillus saitoi.

- control, $O$ : plus corn steep liquor $(2 \%), \times$ : plus wheat bran $(2 \%)$. Only in this experiment (A and B) conidia were collected from the sporulation medium.11) The concentration of sucrose, pectin, and $\mathrm{NaNO}_{3}$ of the main culture medium was $3,0.75$ and $0.58 \%$ respectively $(C / 10=10)$.

\section{The effect of organic nitrogen sources}

Figs. $4 \mathrm{~A}$ and $4 \mathrm{~B}$ also show the effect of organic nitrogen sources upon the enzyme producing ability. It may clearly be said that the addition of organic nitrogen sources, such as corn steep liquor, wheat bran markedly reduced the amount of the enzyme in the medium. Another experiment showed the same tendency, when coprameal, defatted soy bean and urea were added as organic nitrogen sources in addition to $\mathrm{NaNO}_{3}$.

The effect of the amount of carbon source and pectin

It is reasonably considered that the amount of energy or carbon source, i.e., sucrose, and of inducer, i.e., pectin, may affect the yield

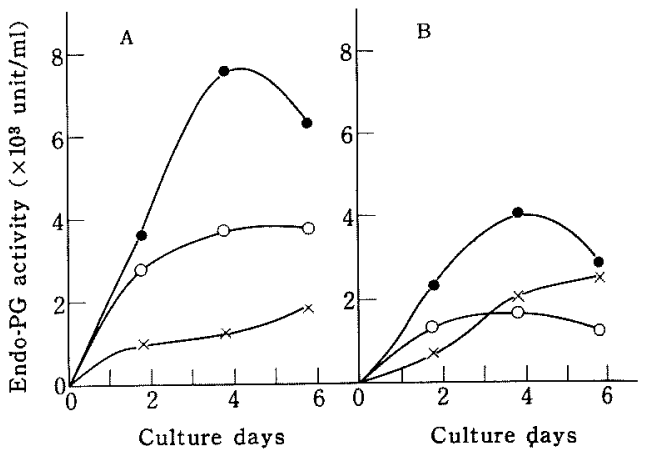

FIG. 5. Effects of the Change in Pectin and Sucrose Amount of the Modified Czapek Medium.

(A): sucrose/pectin=2, (B): sucrose/pectin $=4$ -: sucrose; $4 \%, \quad O$ : sucrose; $3 \%, \quad \times$ : sucrose; $2 \%$

of endo-PG. Figs. $5 \mathrm{~A}$ and $5 \mathrm{~B}$ show the effects of the amount of carbon source and of inducer, when weight ratios of sucrose/pectin were fixed at 2 and 4 respectively. In either case, $\mathrm{C} / \mathrm{N}$ ratio was 10 . The highest activity was observed in the case of sucrose: $4 \%$ and pectin: $2 \%$ among tested. It should be mentioned here about the low enzyme activity compared with that shown in Fig. 4. Transfer of the strain from a sporulation medium ${ }^{111}$ to the bread medium to obtain a large amount of conidia between the experiments shown in Figs. 4 and 5 resulted in the decrease of the enzyme producing ability.

The effects of $\mathrm{C} / \mathrm{N}$ ratio and the presence of ammonium salt

The effects of $\mathrm{C} / \mathrm{N}$ ratio and the presence

TABLE II. THE EFFECTS OF $\mathrm{NH}_{4}$-TARTRATE AND C/N Ratio* on the Production of ENdo-PG. (4 days' culture)

\begin{tabular}{rcc}
$\mathrm{C} / \mathrm{N}$ & \multicolumn{2}{c}{ Endo-PG activity (unit/ml) } \\
& $\begin{array}{c}(-) \\
\mathrm{NH}_{4} \text {-tartrate }\end{array}$ & $\mathrm{NH}_{4}$-tartrate \\
7 & 8,100 & 7,800 \\
8 & 7,600 & 8,400 \\
9 & 7,200 & 8,400 \\
10 & 8,100 & 7,800
\end{tabular}

* Sucrose: $4 \%$, pectin: $2 \% . \mathrm{C} / \mathrm{N}$ ratio was varied with $\mathrm{NaNO}_{3}$.

11) C. Thom and K. B. Raper, "A Manual of the Asper gilli", The Williams and Wilkins Co.. 1945, p. 37. 
of ammonium salt on the enzyme producibility was summarized in Table II. Any remarkable difference was not observed when $\mathrm{C} / \mathrm{N}$ ratio varied from 7 to 10 in the presence or absence of ammonium tartrate.

The effect of the rate of oscillation

The rate of oscillation which relates to the rotation speed and the degree of aeration in a large scale fermentation, was compared between 125 and 100 o.p.m. The former condition was much more aerobic than the latter. The endo-PG rapidly decreased in amount after four days when shaken 125 o.p.m. The reduced aeration seemed better for the production of endo-PG.

\section{A large scale fermentation}

A $300 \mathrm{l}$ scale fermentation in a $400 \mathrm{l}$ fermentor was tried.

For the proliferation of mycelia, the inoculum medium and aerobic conditions were selected. In the final step large scale fermentation, the main culture medium and less aerobic conditions were adopted. The development of the fermentation is shown in Fig. 6. The culture fluid was concentrated by seven times and the enzyme in the medium was

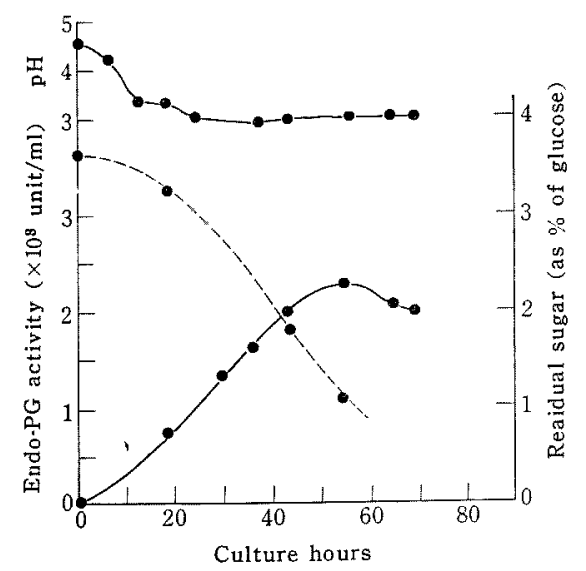

FIG. 6. Progress of a large scale (300 l) fermentation with Asp. saitoi.

activity: - - The concentration of sucrose, pectin and $\mathrm{NaNO}_{3}$ of the main culture medium was 4,2 and $1.15 \%$ respectively $(\mathrm{C} / \mathrm{N}=10)$. precipitated by the addition of twice volume of methanol at $5^{\circ} \mathrm{C}$. About $40 \%$ of the activity in the culture fluid was recovered in the precipitates, although a preliminary experiment showed the over $80 \%$ recovery through this treatment. Several data concerned the fermentation and the preparation of the crude enzyme were listed in Table III.

Table III. The Data Concerned with the Large Scale Fermentation and the Crude ENZYME PREPARATION

Total unit in the medium $5.4 \times 10^{8}$ unit Scale of culture 3001

Maximum activity in the medium 2,200 unit $/ \mathrm{ml}$ Specific activity of the crude enzyme

A mount of the crude enzyme $4.85 \times 10^{4}$ unit $/ \mathrm{g}$ Total unit of the crude enzyme $6.04 \mathrm{~kg}$ Recovery (medium $\rightarrow$ Precipitates) $41 \%$

By the addition of methanol, undegraded or partly degraded pectin was also precipitated, so that the specific activity of the crude enzyme preparation was low.

\section{DISCUSSION}

The endo-PG of Aspergillus saitoi IAM 2217 seemed to be constitutive, because detectable amount of endo-PG was produced in the absence of pectic substances. This observation is consistent with the results concerning the endo-PG production with Asp. niger ${ }^{6.7)}$ The stimulative effect of pectin on the production of endo-PG was also observed as reported with Asp. niger."

Increased activity of endo-PG, however, may partly depend on the induced synthesis of exo-polygalacturonase as stated by Saitô, ${ }^{61}$ because the crude enzyme obtained from pectin plus lots produced more monomer of galacturonic acid from polygalacturonic acid than from pectin minus lots. (See Fig. 3)

Tuttobello et al. ${ }^{7}$ observed that the addition of $2 \%$ of ground nut meal to the medium markedly increased the amount of endo-PG excreted with Asp. niger. According to their 
result, soya flour, corn steep liquor and nutrient broth increased the producibility of endo-PG as well. As for Asp. saitoi IAM 2217, on the contrary, organic nitrogen sources, such as corn steep liquor, coprameal and defatted soy bean were all repressive. In recent years, there are several reports on the repressive effect of amino acids on the exocellular enzyme formation. ${ }^{12 \sim 14}$ But the effect of single or combination of amino acids has not been examined with Asp. saitoi.

As the formation of endo-PG of Asp. saitoi usually reached maximum after $4 \sim 6$ days' shaking culture, the development of endo-PG activity did not accord with the proliferation of mycelia.

It seems better to reduce the proliferation of mycelia from the following facts: (i) The addition of organic nitrogen sources reduced the producibility of endo-PG. (ii) The re-

12) J. Chaloupka and P. Krečkova, Biochem. Biophys. Res. Comm., 8, 120 (1962).

13) R. Neumark and N. Citri, Biochim. Biophys. Acta, 59, 749 (1962).

14) T. Yasui, S. Iwasaki and K. Arima, Proceeding of the Annual Meeting of The Agricultural Chemical Society of Japan. Sapporo, 1964, p. 66 . duced aeration (100 o.p.m.) seemed superior to increased aeration (125 o.p.m.). (iii) The pellet form of mycelia seemed superior to the pulp form, which was thought to be better grown than the pellet form.

Mill and Tuttobello, ${ }^{151}$ in their trial in a 101 jar fermentor, obtained the activity of about 9,000 unit $/ \mathrm{ml}$. While with Asp. saitoi IAM 2217, about 8,000 unit/ml (in Mill et al.' unit) was usually recorded in the shaking flask, but fairly reduced activity (about $2,000 \mathrm{unit} / \mathrm{ml}$ ) was recorded in the $300 \mathrm{l}$ tank fermentor.

The rapid proliferation of mycelia in the tank fermentor may have resulted in the low activity.

Acknowledgement. The authors are grateful to Dr. Gakuzo Tamura, Dr. Yasuji Minoda, and Dr. Jôji Takahashi for their many helpful discussions and suggestions. They also wish to thank Dr. Tetsuo Ishikawa of Meiji Confectionary Co. Ltd. and the members of the division of the pilot plant for operating the 4001 tank fermentor.

15) P. J. Mill and R. Tuttobello, Biochem. J., 79, 57 (1961), 